\title{
Detection of Clostridium difficile in faeces by direct gas liquid chromatography
}

\author{
PN LEVETT
}

From the Anaerobe Reference Unit, Public Health Laboratory, Luton and Dunstable Hospital, Lewsey Road, Luton LU4 ODZ

SUMMARY Stool specimens examined for the presence of Clostridium difficile and its cytotoxin were screened by gas liquid chromatography for the presence of volatile fatty acids and $p$-cresol. Twenty seven of $110(25 \%)$ stools yielded $C$ difficile or cytotoxin; iso-valeric acid was detected in $63 / 110(57 \%)$ and iso-caproic acid in 18/110 (16\%) stools. Para-cresol was found in 24/71 (34\%) stools examined. Iso-valeric acid was detected in $85 \%$ of stools positive for $C$ difficile, whereas iso-caproic acid $(41 \%)$ and $p$-cresol $(52 \%)$ were found in much lower numbers of $C$ difficile-positive stools.

It is concluded that gas chromatographic detection of volatile fatty acids or $p$-cresol in faeces are not satisfactory screening tests for the presence of $C$ difficile.

The development of efficient selective media ${ }^{1-3}$ and isolation procedures ${ }^{4}$ have greatly simplified the detection of Clostridium difficile in stool specimens, enabling many laboratories lacking the facilities for cytotoxin assay to screen specimens for the organism.

Isolation of $C$ difficile, however, generally requires at least $48 \mathrm{~h}$ incubation. For those laboratories without access to tissue culture facilities a rapid method for the detection of $C$ difficile in faeces would be of considerable value. The use of counter-immunoelectrophoresis to detect the cytotoxin of $C$ difficile has been reported, ${ }^{5-7}$ but the value of this test is reduced by the use of impure antitoxin preparations. ${ }^{89}$ A fluorescent antibody test applied to stool smears detected $81 \%$ of $C$ difficile positive stools from patients with antibiotic associated diarrhoea, ${ }^{10}$ but many cross reactions were noted between antisera raised against $C$ difficile and other clostridia. In addition, a high proportion of false positive results was observed in stools from normal adults and patients with diarrhoea not associated with antibiotics. Examination of Gram stained films of faeces was found to be of little value in the diagnosis of $C$ difficile infection."

Gas liquid chromatography of stool specimens has been employed, ${ }^{12}$ but doubts have been expressed about the predictive value of this test. ${ }^{13}$ This paper reports the results of an attempt to predict the pres-

Accepted for publication 19 October 1983 ence of $C$ difficile in stools on the basis of gas chromatographic detection of volatile fatty acids and of $p$-cresol.

\section{Material and methods}

\section{STOOLS}

One hundred and ten stool specimens were received from hospitals throughout the United Kingdom. All samples examined were from patients suspected of suffering from $C$ difficile-associated diarrhoea.

\section{MEDIA}

Modified cycloserine cefoxitin fructose agar (CCFA medium $)^{3}$ was prepared containing $C$ difficile agar base (Oxoid CM601) $69 \mathrm{~g} / \mathrm{l} ; 50 \%$ fresh egg yolk emulsion $36 \mathrm{ml} / \mathrm{l}$; freeze dried cycloserine and cefoxitin (Oxoid SR96) $250 \mu \mathrm{g} / \mathrm{ml}$ and $8 \mu \mathrm{g} / \mathrm{ml}$, respectively; $2 \%(\mathrm{wt} / \mathrm{vol})$ neutral red solution $1.4 \mathrm{ml} / \mathrm{l}$; and p-hydroxy phenyl acetic acid $1 \mathrm{~g} / \mathrm{l}$.

Cooked meat broths containing dried meat granules (Lab M Lab 24) $37.5 \mathrm{~g} / \mathrm{l}$, brain heart infusion (Lab M Lab 49) $17.5 \mathrm{~g} / \mathrm{l}$, yeast extract (Oxoid L21) $6 \mathrm{~g} / \mathrm{l}$, and haemin/menadione solution (Gibco) $10 \mathrm{ml} / \mathrm{l}$ were dispensed into universal containers and autoclaved at $121^{\circ} \mathrm{C}$ for $15 \mathrm{~min}$.

Plates containing 5\% horse blood agar were obtained commercially (Lab M).

\section{CULTURE}

All specimens were cultured directly onto modified CCFA selective medium ${ }^{3}$ and were also subjected to 
alcohol treatment ${ }^{4}$ followed by plating onto blood agar and CCFA medium. In addition, two cooked meat broths were inoculated with each specimen before and after alcohol treatment. After incubation at $37^{\circ} \mathrm{C}$ for five days these broths were sub-cultured onto blood agar and CCFA medium. All plates were incubated in an anaerobic cabinet at $37^{\circ} \mathrm{C}$ for $48 \mathrm{~h}$.

\section{IDENTIFICATION}

All colony types with typical morphology were subcultured onto blood agar plates and identified using the criteria of Holdeman et al..$^{14}$

\section{CYTOTOXIN ASSAY}

A suspension of faecal material was made in sterile phosphate buffered saline (PBS) containing penicillin $(1000 \mu \mathrm{g} / \mathrm{ml})$, streptomycin $(1000 \mu \mathrm{g} / \mathrm{ml})$, and metronidazole $(100 \mu \mathrm{g} / \mathrm{ml})$. After centrifugation at $2000 \mathrm{~g}$ for $20 \mathrm{~min}$, cytotoxicity was assayed on MRC V tissue culture monolayers. A characteristic cytopathic effect neutralised by $C$ difficile antitoxin was considered positive.

\section{GAS LIQUID CHROMATOGRAPHY}

A $50 \%$ (wt/vol) suspension of faecal material was prepared in $1 \mathrm{ml}$ PBS (without antibiotics). This was acidified with $0.2 \mathrm{ml} 50 \% \mathrm{H}_{2} \mathrm{SO}_{4}$ and extracted in 1 $\mathrm{ml}$ diethyl ether. Samples $(1 \mu \mathrm{l})$ were assayed by gas chromatography for the presence of volatile fatty acids and $p$-cresol.

Volatile fatty acids were analysed using a Pye Unicam Series 104 gas chromatograph equipped with a flame ionisation detector, employing a $1.5 \mathrm{~m}$ $\times 4 \mathrm{~mm}$ id glass column packed with $10 \%$ FFAP on diatomite CLQ (JJ's Chromatography). The oven temperature was $150^{\circ} \mathrm{C}$ and the carrier gas was nitrogen at a flow rate of $50 \mathrm{ml} / \mathrm{min}$.

Para-cresol was detected in a similar fashion, using a column packing of $3 \%$ OV1 on diatomite CLQ (JJ's Chromatography) and an oven temperature of $110^{\circ} \mathrm{C}$.

\section{Results}

Of 110 stools investigatcd, $27(25 \%)$ contained $C$ difficile or cytotoxin. Eighteen stools (16\%) were positive for cytotoxin; only one stool was cytotoxin positive and culture negative. The distribution of fatty acids in the series acetic to caproic was acetic $(92 / 110)$, propionic $(75)$, iso-butyric $(61)$, butyric (68), valeric (29), iso-caproic (18), and caproic (0). No association was found between the presence of $C$ difficile or cytotoxin and acetic, propionic, isobutyric, butyric, or valeric acids.

Significant associations were apparent between $C$ difficile and iso-valeric acid $\left(\chi^{2}=9.83\right.$ with Yates' correction, $p<0.01)$ and between $C$ difficile and iso-caproic $\left(\chi^{2}=13.375\right.$ with Yates' correction, $\mathrm{p}<$ $0 \cdot 001)$. Iso-valeric acid was detected in $23 / 27(85 \%)$ stools positive for $C$ difficile (Table), but only $11 / 27$ (41\%) stools positive for $C$ difficile contained isocaproic acid.

Para-cresol was found in $24 / 71(34 \%)$ stools. Of these 71 stools, $21(30 \%)$ were positive for $C$ difficile or cytotoxin; $p$-cresol was found in 11/21 (52\%) stools containing $C$ difficile (Table).

No combination of iso-valeric and iso-caproic acids and $p$-cresol produced a better correlation with the presence of $C$ difficile or cytotoxin than iso-valeric acid alone. Moreover, when multiple specimens from the same patient were examined over six weeks the presence of iso-valeric acid, isocaproic acid, and $p$-cresol did not correlate well with the detection of $C$ difficile.

\section{Discussion}

A previous study indicated that gas chromatographic detection of iso-caproic acid might be a useful screening test for the presence of $C$ difficile in stools. The authors' interpretation of their data was questionable, however ${ }^{13}{ }^{15}$; the results of the present study essentially confirm those of Potvliege et al,,$^{12}$ but the interpretation placed on them is quite different.

A significant association was found between the presence of iso-caproic acid and the detection of $C$ difficile. This was not unexpected since $C$ difficile is one of relatively few common gut organisms that produce iso-caproic acid in vitro. ${ }^{14}$ Caution must be exercised before any reliance is placed on this association, however, since there is no guarantee

Association of Clostridium difficile with iso-valeric acid, iso-caproic acid, and p-cresol in stools

\begin{tabular}{lllll}
\hline Metabolite & $\begin{array}{l}\text { No of stools } \\
\text { examined }\end{array}$ & $\begin{array}{l}\text { No of stools } \\
\text { positive for } \\
\text { metabolite } \\
\text { and } \\
\text { C difficile }\end{array}$ & $\begin{array}{l}\text { No of stools } \\
\text { positive for } \\
\text { metabolite } \\
\text { but not } \\
\text { C difficile }\end{array}$ & $\begin{array}{l}\text { No of stools } \\
\text { positive for } \\
\text { C difficile } \\
\text { but not } \\
\text { metabolite }\end{array}$ \\
\hline $\begin{array}{l}\text { Iso-valeric acid } \\
\text { Iso-caproic acid }\end{array}$ & 110 & 23 & 40 & 4 \\
$p$-cresol & 110 & 11 & 7 & 16 \\
\hline
\end{tabular}


that metabolic end products in vitro are the same as those elaborated in vivo. In addition, other organisms that produce iso-caproic acid in vitro, such as $C$ bifermentans, $C$ sordellii, and $C$ sporogenes, are commonly isolated from stools. ${ }^{16}$ Of paramount importance, however, is the finding that only $41 \%$ of $C$ difficile-positive stools contained iso-caproic acid, implying a false negative rate of $59 \%$. Even when iso-caproic acid and $C$ difficile are found in the same stool, this correlation may be only intermittent.

Of the volatile acids studied, iso-valeric acid showed the greatest predictive value, being found in $85 \%$ of stools positive for $C$ difficile. The high proportion of false positive results with iso-valeric acid may reflect the much wider range of intestinal organisms which produce this compound in vitro.

Production of $p$-cresol has been used as an aid to the presumptive identification of $C$ difficile. ${ }^{3} \mathrm{~A}$ high rate of false negatives $(48 \%)$ is again quite unacceptable. In addition, most stools containing $p$-cresol did not yield $C$ difficile. Since a combination of isolation methods was employed this finding suggests that other organisms in the intestines may produce $p$-cresol, although previous reports have been contradictory. ${ }^{17} 18$

It is concluded that detection of volatile fatty acids or $p$-cresol in stools are not satisfactory screening tests for $C$ difficile.

I wish to thank Dr AT Willis for his critical reading of the manuscript.

\section{References}

' George WL, Sutter VL, Citron DM, Finegold SM. Selective and differential medium for isolation of Clostridium difficile. J Clin Microbiol 1979;9:214-9.

${ }^{2}$ Willey SH, Bartlett JG. Cultures for Clostridium difficile in stools containing a cytotoxin neutralised by Clostridium sordellii antitoxin. J Clin Microbiol 1979;10:880-4.

${ }^{3}$ Phillips KD, Rogers PA. Rapid detection and presumptive identification of Clostridium difficile by $p$-cresol production on a selective medium. J Clin Pathol 1981;34:642-4.
4 Borriello SP, Honour P. Simplified procedure for the routine isolation of Clostridium difficile from faeces. J Clin Pathol 1981;34:1124-7.

${ }^{5}$ Welch DF, Menge SK, Matsen JM. Identification of toxigenic Clostridium difficile by counterimmunoelectrophoresis. J Clin Microbiol 1980;11:470-3.

- Ryan RW, Kwasnik I, Tilton RC. Rapid detection of Clostridium difficile toxin in human faeces. $J$ Clin Microbiol 1980;12:776-9.

' Wu TC, Fung JC. Evaluation of the usefulness of counterimmunoelectrophoresis for diagnosis of Clostridium difficileassociated colitis in clinical specimens. J Clin Microbiol 1983;17:610-3.

8 Poxton IR, Byme MD. Detection of Clostridium difficile toxin by counterimmunoelectrophoresis: a note of caution. J Clin Microbiol 1981;14:349.

${ }^{9}$ West SEH, Wilkins TD. Problems associated with counterimmunoelectrophoresis assays for detecting Clostridium difficile antigen. J Clin Microbiol 1982;15:347-9.

${ }^{10}$ Wilson KH, Silva J, Fekety FR. Fluorescent-antibody test for detection of Clostridium difficile in stool specimens. J Clin Microbiol 1982;16:464-8.

" Shanholtzer CJ, Petersen LR, Olson MN, Gerding DN. Prospective study of Gram-stained stool smears in diagnosis of Clostridium difficile colitis. J Clin Microbiol 1983;17:906-8.

${ }^{12}$ Potvliege C, Labbé M, Yourassowsky E. Gas-liquid chromatography as screening test for Clostridium difficile. Lancet 1981;ii: 1105 .

${ }^{13}$ Borriello SP. Gas-liquid chromatography and Clostridium difficile. Lancet 1981;ii: 1283.

14 Holdeman LV, Cato EP, Moore WEC. Anaerobe Laboratory Manual, 4th edn. Blacksburg: Virginia Polytechnic Institute, 1977.

${ }^{15}$ Levett PN. Gas chromatography of stools and the detection of Clostridium difficile. In: Proceedings of the Anaerobe Discussion Group Symposium, Cambridge 1983. The Hague: Martinus Nijhoff (in press).

16 Willis AT. Clostridia of wound infection. London: Butterworths, 1969.

${ }^{17}$ Bone E, Tamm A, Hill M. The production of urinary phenols by gut bacteria and their possible role in the causation of large bowel cancer. Am J Clin Nut 1976;29:1448-54.

${ }^{18}$ Elsden SR, Hilton MG, Waller JM. The end products of the metabolism of aromatic amino acids by clostridia. Arch Microbiol 1976;107:283-8.

Requests for reprints to: PN Levett, Public Health Laboratory, Luton and Dunstable Hospital, Lewsey Road, Luton LU4 0DZ, England. 